\title{
Inter Conversion of Somatic and Cancer Stem Cell: From Discovery to New Paradigm in Cancer Therapy
}

\section{Shashank Kumar*}

Centre for Biochemistry and Microbial Sciences, Central University of Punjab, Bathinda-151001, Punjab, India

\section{Letter to Editor}

Organ is composed of special type of tissue and cells. Deficits in functionality and number of particular cells lead to the development of various type of human disease such as diabetes, neurological disease, cardiovascular, hepatic disorder and cancer etc. In the world of chronic disease there is a need of new branch of medicine that might help in the regeneration of tired and failing organ system. Present scientific community is giving emphasis and hope that regeneration of tired and failing organ system which results into various disease and disorders, might be cured/mitigated by special type of cells known as stem cells.

Ernst Haeckel, a German biologist, used the term "Stammzelle" (German for stem cell) to describe the ancestor unicellular organism from which all multicellular organisms evolved $[1,2]$. Literature revealed that Haeckel used the term stem cell in two sense "unicellular ancestor of all multicellular organisms" and as "the fertilized egg that gives rise to all cells of the organism". The concept of stem cells was established in the late $19^{\text {th }}$ century. Embryonic cells became a concern for pathologists at the beginning of $20^{\text {th }}$ century, attempting to explain tumor genesis. After 1950, early work on embryonic cells and tumors led to the modern stem cell research [3]. In early $20^{\text {th }}$ century it was thought that cellular differentiation can only be a unidirectional process. It was believed that the mature cells were permanently locked into the differentiated state and cannot return to a full mature, pluripotent stem cell state. However, the question still remained whether an intact differentiated cell could be fully reprogrammed to become pluripotent. In 1962, John B. Gurdon shifted this paradigm by demonstrating that differentiated somatic cell nuclei had the potential to revert to pluripotency [4]. After a long period of about 50 years, a fundamental discovery was done by Yamanaka. First time he demonstrated that an intact differentiated somatic cell could be reprogrammed to become pluripotent [5]. In the very next year in 2007, Yamanaka and his colleague first time isolated human embryonic stem cells (ESCs) and generated induced pluripotent stem cells (iPSCs) from terminally differentiated somatic cells $[5,6]$. In his study he used four transcription factors (initially 24 factors) Myc, Oct3/4, Sox 2 and Klf4, are known as Yamanaka Factors. Yamanaka and John Gurdon (his fellow stem cell researcher) were jointly awarded the Nobel Prize in Physiology or Medicine, in 2012 for the discovery "mature cells can be reprogrammed to become pluripotent".

Although the discovery by Yamanaka opened up a completely new research field but there were a lot to do in the field. Further researchers improved the delivery mechanisms of pluripotency factors; identified the various transcription factors required for pluripotency induction in different cell types; identified small functional substitute molecules for transcription factors; standardized trans-differentiation experiments (exocrine-endocrine cells, fibroblast-myoblast cells, fibroblast-cardiomyocyte cells and fibroblast cells to neurons). By 2012 many reports described functional cell differentiation but in mid-2013, Takanori and Hideki successfully generated a $3 \mathrm{D}$ vascularized and functional organ (liver) from human iPScs. This 3D structure was able to form functional vasculatures into liver tissue (where transplanted) and were also performed the liver specific functions such as production of proteins and drug metabolism. This was the first report demonstrating the generation of a functional human organ from pluripotent stem cells [7]. Efforts are needed to translate this promising knowledge for the treatment of patients.

Cancer cell may produce cancer differentiation cells and cancer stem cells. Cells having self-renewal and differentiation property are known as stem cells. Cancer stem cell is different from cancer cells as they have both differentiation as well as self-renewal properties. Each cancer stem cell has potential to diversify again into different lineage of cancer stem cells by dedifferentiation process leading into the formation of heterogeneous tumor $[8,9]$. Cancer stem cell may divide symmetrical, asymmetrical or symmetrical self-renewal to produce a set of two differentiated cell, one differentiated and one cancer stem cell or two cancer stem cells respectively. Under normal condition the decreasing order of division type is symmetric $>$ asymmetric $>$ symmetric self-renewal. Due to chemotherapy or radiotherapy the sequence might change in the following decreased order symmetric selfrenewal>symmetric $>$ asymmetric. Self-renewal symmetric differentiation largely contributes to the resistance and reoccurrence of tumors [10]. It has been reported that CSCs have capability to invade and get involved in metastasis. For this property they are also known as the key metastatic players of tumors. Oncogenic Ras and its important downstream target Myc is known to initiate the malignant transformation in CSCs [11]. A balanced equilibrium between differentiated cells (committed to tissue lineages) and cells with stem-like characteristics is the basis for the proper development of multicellular organism. When the intrinsic factor (e.g. transcriptional and epigenetic) equilibrium of a stem cell disturbed either with the effect of cell microenvironment or due to mutation accumulation, the cell converts into cancer stem cell (CSC). A functional characteristic microenvironment known as "niche" is required in the form of habitat of certain cells with specific functions. Several factors such as immune cells, ECM components, hypoxia and $\mathrm{pH}$ etc. are known to regulate this microenvironment [12-14].

Stem cell research in therapy might be divided into two major streams first "use of stem cell property for the generation of retired or failed tissue" and second "targeting the cancer stem cells to prevent cancer relapse and to increase the efficacy of cancer therapy". In the previous section of this article it has been mentioned that stem cell might be utilized for the regeneration of organs in case of chronic disease. In the last few years it has been demonstrated that cancer stem cells have

*Corresponding author: Dr. Shashank Kumar, Assistant Professor, Centre for Biochemistry and Microbial Sciences, Central university of Punjab, Bathinda-151001, Punjab, India, Tel: +91 9335647413; E-mail: shashankbiochemau@gmail.com

Received June 20, 2017; Accepted July 10, 2017; Published July 18, 2017

Citation: Kumar S (2017) Inter Conversion of Somatic and Cancer Stem Cell: From Discovery to New Paradigm in Cancer Therapy. J Cytol Histol 8: 465. doi: 10.4172/2157-7099.1000465

Copyright: ( 2017 Kumar S. This is an open-access article distributed under the terms of the Creative Commons Attribution License, which permits unrestricted use, distribution, and reproduction in any medium, provided the original author and source are credited. 
Citation: Kumar S (2017) Inter Conversion of Somatic and Cancer Stem Cell: From Discovery to New Paradigm in Cancer Therapy. J Cytol Histol 8: 465. doi: 10.4172/2157-7099.1000465

special type of niche having hypoxia and decreased $\mathrm{pH}$ environment. They together produce and increase stemness, cell differentiation, angiogenesis, immunosuppression and chemo resistance in the niche and its neighbour cells $[12,15,16]$. It might be inferred that targeting the pathways involved in hypoxia condition, angiogenesis and double DNA break repair system in cancer stem cells would be a better strategy for selective targeting of these cells. It is hereby also recommended that there is more rapid research in stem cell application is needed to fight against devastating diseases such as cancer.

\section{Acknowledgement}

SK acknowledges Department of Science and Technology, India, for providing financial support in the form of DST-SERB Grant [EEQ/2016/000350]. SK also acknowledges Central University of Punjab, Bathinda for providing necessary infrastructure facility.

\section{References}

1. Haeckel E (1868) Naturliche Schopfungsgeschichte. Berlin: Georg Reimer.

2. Haeckel E (1874) Anthropogenie (1stedn), Leipzig: Wilhelm Engelmann.

3. Andreas-Holger M (2011) Ambiguous Cells: The Emergence of the Stem Cell Concept in the Nineteenth and Twentieth Centuries. Notes and records of the Royal Society of London 65: 359-378.

4. Gurdon JB (1962) The developmental capacity of nuclei taken from intestinal epithelium cells of feeding tadpoles. J Embryol Exp Morphol 10: 622-640.

5. Takahashi K, Yamanaka S (2006) Induction of pluripotent stem cells from mouse embryonic and adult fibroblast cultures by defined factors. Cell 126: 663-676

6. Yu J, Vodyanik MA, Smuga-Otto K, Antosiewicz-Bourget J, Frane JL, et al.
(2007) Induced pluripotent stem cell lines derived from human somatic cells Science 318: 1917-1920.

7. Takebe T, Sekine K, Enomura M, Koike H, Kimura M, et al. (2013) Vascularized and functional human liver from an iPSC-derived organ bud transplant. Nature 499: 481-484.

8. Meacham CE, Morrison SJ (2013) Tumour heterogeneity and cancer cell plasticity. Nature 501: 328-337.

9. Islam F, Gopalan V, Smith RA, Lam AK (2015) Translational potential of Cancer Stem Cells: A review of the detection of Cancer Stem Cells and their roles in cancer recurrence and cancer treatment. Exp Cell Res 335: 135-147.

10. Lee G, Hall III RR, Ahmed AU (2016) Cancer stem cells: cellular plasticity niche, and its clinical relevance. J Stem Cell Res Ther 6: 1-20.

11. Friedmann-Morvinski D, Verma IM (2014) Dedifferentiation and reprogramming: origins of cancer stem cells. EMBO Reports 15: 244-253.

12. Hjelmeland $A B, W u Q$, Heddleston JM, Choudhary GS, MacSwords J, et al. (2011) Acidic stress promotes a glioma stem cell phenotype. Cell Death Differ 18: $829-840$

13. Ye J, Wu D, Wu P, Chen Z, Huang J (2014) The cancer stem cell niche: cross talk between Cancer Stem Cells and their microenvironment. Tumour Biol 35: 3945-3951.

14. Oskarsson T, Batlle E, Massague J (2014) Metastatic stem cells: sources, niches, and vital pathways. Cell Stem Cell 14: 306-321.

15. Gerweck LE, Seetharaman K (1996) Cellular pH gradient in tumor versus normal tissue: potential exploitation for the treatment of cancer. Cancer Res 56: 1194-1198.

16. Chiche J, Brahimi-Horn MC, Pouyssegur J (2010) Tumour hypoxia induces a metabolic shift causing acidosis: a common feature in cancer. J Cell Mol Med 14: 771-794. 